\title{
Cytokine and growth factor profiling in patients with the metabolic syndrome
}

\author{
Seyed Reza Mirhafez ${ }^{1,2} \dagger$, Alireza Pasdar ${ }^{2,3}$, Amir Avan ${ }^{2} \dagger$, Habibollah Esmaily ${ }^{4}$, Atefeh Moezzi ${ }^{5}$, \\ Mohsen Mohebati ${ }^{5}$, Zahra Meshkat ${ }^{2}$, Hassan Mehrad-Majd ${ }^{1}$, Saied Eslami ${ }^{6,7}$, Hamid Reza Rahimi ${ }^{2}$, \\ Hamed Ghazavi ${ }^{8}$, Gordon A. Ferns ${ }^{9}$ and Majid Ghayour-Mobarhan ${ }^{2,5,10_{*}}$ \\ ${ }^{1}$ Department of Basic Medical Sciences, Neyshabur University of Medical Sciences, Neyshabur, Iran \\ ${ }^{2}$ Department of New Science and Technologies, School of Medicine, Mashbad University of Medical Sciences, Mashbad, Iran \\ ${ }^{3}$ Division of Applied Medicine, Medical School, University of Aberdeen, Foresterbill, Aberdeen AB25 2ZD, UK \\ ${ }^{4}$ Department of Biostatistics and Epidemiology, School of Medicine, Mashbad University of Medical Sciences, Mashbad, Iran \\ ${ }^{5}$ Cardiovascular Research Center, School of Medicine, Mashbad University of Medical Sciences, Mashbad, Iran \\ ${ }^{6}$ Department of Medical Informatics, School of Medicine, Mashbad University of Medical Sciences, Mashbad, Iran \\ ${ }^{7}$ Pharmaceutical Research Center, School of Pharmacy, Mashbad University of Medical Sciences, Mashbad, Iran \\ ${ }^{8}$ Department of Medical Biotechnology, School of Medicine, Mashbad University of Medical Sciences, Mashbad, Iran \\ ${ }^{9}$ Division of Medical Education, Brighton E Sussex Medical School, Falmer, Brighton, Sussex BN1 9PH, UK \\ ${ }^{10}$ Biochemistry of Nutrition Research Center, Faculty of Medicine, Mashbad University of Medical Science, \\ Mashbad 99199-91766, Iran
}

(Submitted 28 August 2014 - Final revision received 19 February 2015 - Accepted 4 March 2015 - First published online 20 May 2015)

\section{Abstract}

The metabolic syndrome (MetS) is associated with a pro-inflammatory milieu that may partially account for its association with an increased cardiovascular risk. We aimed to (1) evaluate the serum concentrations of twelve cytokines and growth factors (epidermal growth factor (EGF), interferon- $\gamma$ (IFN- $\gamma$ ), IL-1 $\alpha /-1 \beta /-2 /-4 /-6 /-8 /-10$, monocyte chemoattractant protein-1 (MCP-1), TNF- $\alpha$ and vascular endothelial growth factor (VEGF)) in 303 individuals with or without the MetS; and (2) explore their relationship with the presence of the MetS. Patients with the MetS had significantly higher serum concentrations of IFN- $\gamma$, EGF, IL-1 $\alpha /-1 \beta /-2 /-4 /-6 /-8 /-10$, MCP-1 and TNF- $\alpha$, whilst serum VEGF concentrations were markedly lower compared with the control group (e.g. $38.55 v .82 \cdot 18 \mathrm{pg} / \mathrm{ml} ; P<0 \cdot 05$ ). Amongst these parameters, IFN- $\gamma$ and IL- $1 \alpha$ emerged as the most significant independent predictors of the MetS. In conclusion, our findings demonstrate that patients with the MetS had an altered blood cytokine and growth factor profile that may partially account for its adverse clinical outcomes. Further prospective studies in larger multi-centre settings are required to unravel the role and association of the emerging biomarkers with the MetS and their implication in therapeutic intervention.

\section{Key words: Metabolic syndrome: Diabetes: Inflammation: Cytokines: Growth factors}

The metabolic syndrome (MetS) is a common metabolic condition that is characterised by a clustering of biochemical and clinical characteristics, including central adiposity and insulin resistance. It is associated with an increased risk of both diabetes ${ }^{(1)}$ and $\mathrm{CVD}^{(2-6)}$. The prevalence of the MetS has increased globally in the past few decades, and this may be related to the increasing prevalence of obesity and diabetes. Impaired glucose tolerance, dyslipidaemia and hypertension are features of the MetS, and more recently a low-grade systemic inflammation has been reported to be associated with it ${ }^{(7)}$. Obesity is also associated with a chronic inflammatory response that includes activation of inflammatory signalling pathways, abnormal cytokine production and an increased acute-phase response ${ }^{(8)}$. Moreover, circulating levels of inflammatory markers, such as C-reactive protein $(\mathrm{CRP})^{(9)}$ fibrinogen ${ }^{(10)}$, and pro-inflammatory cytokines, such as IL- $6^{(11)}$ IL-10 ${ }^{(12)}$ and TNF- $\alpha^{(13)}$, have been reported to be associated with the MetS ${ }^{(14)}$. IL- $1 \alpha$ and IL-1 $\beta$ as members of IL-1 family are both responsible for a variety of inflammatory and metabolic effects. However, the data have not been

\footnotetext{
Abbreviations: CRP, C-reactive protein; DBP, diastolic blood pressure; EGF, epidermal growth factor; IFN- $\gamma$, interferon- $\gamma$; MCP-1, monocyte chemoattractant protein-1; MetS, metabolic syndrome; MUMS, Mashhad University of Medical Sciences; SBP, systolic blood pressure; VEGF, vascular endothelial growth factor.
}

*Corresponding author: M. Ghayour-Mobarhan, fax +98 5118002287; email ghayourm@mums.ac.ir

† These authors equally contributed. 
consistent $^{(15-17)}$. Furthermore, a great number of experimental and epidemiological studies suggest that low-grade inflammation links variables, particularly attributed to the MetS, to the increased risk of CVD. It is known that a lowgrade systemic inflammation precedes and predicts the progress of both diabetes and atherothrombotic diseases. The mild inflammatory state is associated with insulin resistance and obesity ${ }^{(18)}$. However, Matsushita et al. ${ }^{(17)}$ studied 624 middle-aged Japanese men without a history of CVD or cancer and reported no significant associations of TNF- $\alpha$ and IL-6 with the MetS or its components. These inconsistent findings may be explained by several reasons, including variations in lifestyle, including diet, severity of associated disease, small sample size, ethnic origin and concurrent medication. Since in previous studies the relationship between the MetS and CVD and a limited numbers of individual inflammatory markers were assessed, in the present study we have measured the serum concentrations of a profile of twelve biomarkers of various categories (pro-inflammatory, anti-inflammatory and growth factors: epidermal growth factor (EGF), interferon- $\gamma$, IL-1 $\alpha$, IL-1 $\beta$, IL-2, IL-4, IL-6, IL-8, IL-10, monocyte chemoattractant protein-1 (MCP-1), TNF- $\alpha$ and vascular endothelial growth factor (VEGF)) in groups of individuals with or without the MetS.

\section{Methods}

\section{Phenotypic definition of the metabolic syndrome}

We used the International Diabetes Federation criteria to define the MetS, according to which the MetS is defined by the following characteristics: central obesity (defined as waist circumference of $\geq 94 \mathrm{~cm}$ for male or $\geq 80 \mathrm{~cm}$ for female) plus any two of the following four factors: raised TAG: $\geq 150 \mathrm{mg} / \mathrm{dl}(1.7 \mathrm{mmol} / \mathrm{l})$; reduced HDL-cholesterol: $<40 \mathrm{mg}$ / $\mathrm{dl}(1.03 \mathrm{mmol} / \mathrm{l})$ in males $<50 \mathrm{mg} / \mathrm{dl}(1.29 \mathrm{mmol} / \mathrm{l})$ in females; raised systolic blood pressure $(\mathrm{SBP}) \geq 130$ or diastolic blood pressure $(\mathrm{DBP}) \geq 85 \mathrm{mmHg}$; raised fasting blood glucose $\geq 100 \mathrm{mg} / \mathrm{dl}(5.6 \mathrm{mmol} / \mathrm{l})$.

\section{Population}

A total of 303 participants were recruited, including 155 patients with the MetS and 148 controls without the MetS from Mashhad (Iran) who had no known history of infectious diseases or major systemic inflammation and were without a family history of stroke, myocardial infarction and diabetes mellitus. The population samples were recruited from Mashhad city and the surrounding regions in northeast Iran.

Exclusion criteria were medical illnesses such as chronic liver and/or renal diseases, pregnant women and alcohol consumption based on a questionnaire, taking any drugs including dietary supplements and anti-inflammatory drugs including aspirin and non-steroidal anti-inflammatory drugs. All participants completed a standardised questionnaire including the following information: sex, ethnicity, age, dietary habits, family history of myocardial infarction, stroke, diabetes mellitus and past medical history. In addition, dietary intake was determined by means of a questionnaire that was designed on the basis of a 24-h dietary recall. Analysis of macronutrient intake was performed using Diet Plan 6 software (Forestfield Software Limited). A trained interviewer performed face-to-face interviews, and individuals were asked about all foods and beverages that were consumed. Informed consent was obtained from all participants using protocols approved by the Ethics Committee of the Mashhad University of Medical Sciences (MUMS).

\section{Anthropometric measurements}

Anthropometric parameters (height, body weight, waist and hip circumference) were measured using standardised procedures, as described ${ }^{(19)}$. BMI was calculated as body weight $(\mathrm{kg})$ divided by squared height in meters $\left(\mathrm{m}^{2}\right)$, and BMI of $20-24.9$, $\geq 25-29.9$ and $\geq 30 \mathrm{~kg} / \mathrm{m}^{2}$ were considered as normal, over-weight or obese, respectively. SBP and DBP (SBP or DBP) were measured in duplicate by sphygmomanometers. Total cholesterol, HDL, LDL and TAG, and fasting blood glucose concentrations were evaluated by standard enzymatic techniques, while serum CRP levels were determined by polyethylene glycol-enhanced immunoturbidimetry, as described previously ${ }^{(19)}$.

\section{Measurement of cytokines and growth factors}

The concentrations of serum cytokines and growth factors, including IL-1 $\alpha$, IL-1 $\beta$, IL-2, IL-4, IL-6, IL-8, IL-10, TNF- $\alpha$, IFN- $\gamma$, MCP-1, EGF and VEGF, were measured using the EV 3513 cytokine biochip array (Randox Laboratories) and competitive chemiluminescence immunoassays (Randox Laboratories), according to the manufacturer's instructions ${ }^{(20,21)}$, using the Randox Evidence Investigator. The Evidence Investigator is an automated analyser for the simultaneous detection of multiple cytokines from a single sample and uses sandwich chemiluminescent methods ${ }^{(20,21)}$. Quantitative and qualitative results are also available. Intra- and inter-assay $\mathrm{CV}$ for most cytokine markers were $\leq 10 \%$ (see online Supplementary Table S1). Randox cytokine controls are intended for use as an assayed quality control in the routine monitoring of accuracy and precision for the analyses listed in this study.

\section{Network analysis}

Functional and physical interactions between pro- and anti-inflammatory factors were retrieved using STRING ${ }^{(22)}$. Data were analysed using Cytoscape version 2.8.3 (an opensource Java tool), and networks were merged with embedded analysis tools, while the Biological Networks Gene Ontology plug-in provided ontologies for the cluster analyses ${ }^{(22)}$.

\section{Statistical analysis}

Data were analysed using SPSS-16 software (SPSS, Inc.). The normality of distribution was assessed using the Kolmogorov-Smirnov test. Descriptive statistics including mean, frequency and standard deviation were determined 
for all variables and was expressed as means with standard deviations for normally distributed variables (or as the median and interquartile range for non-normally distributed variables). For normally and non-normally distributed variables, Student's $t$ test and Mann-Whitney $U$ test were used to compare the clinical characteristics and baseline demographics between the groups, respectively. The $\chi^{2}$ test and/or Fisher's exact test was used for comparing categorical variables. The correlations between the cytokines and growth factors were assessed using Spearman's correlation analysis. Logistic regression analysis was used to calculate association of serum cytokines level and the MetS in present of confounders such as age, sex, smoking and dietary intake. Multivariate analysis was then undertaken for the variables that had a $P<0.05$ in the univariate analysis. Residual regression was used for adjusting of total energy intake. All the analyses were two-sided and statistical significance was set at $P<0 \cdot 05$.

\section{Results}

\section{Clinical characteristics of the population}

The clinical and baseline characteristics of patients with and without the MetS are summarised in Tables 1 and 2 . Individuals with the MetS had a significantly higher BMI, waist circumference, hip circumference, fasting blood glucose, high-sensitivity CRP, TAG, SBP and DBP $(P<0.05)$, while no differences were found for age, sex, height, serum total cholesterol and LDL cholesterol between the groups (Table 1). Moreover, we measured fat percentage and waist: hip ratio in our population. These data showed that the ratio of waist:hip measurements was significantly $(P<0.05)$ increased in the MetS group, compared with the control group. Moreover, the mean and standard deviations of macronutrients and their $P$-values are presented in Table 2 . In the present study, the mean total energy intake in the MetS group was less than that of control groups $(P=0.027)$. The mean intakes of protein, total fat, SFA, MUFA and PUFA in the MetS group were less than those of control groups $(P<0.05)$; however, after adjusting for total energy intake, significant differences remained for total fat, MUFA and PUFA $(P<0 \cdot 05)$

\section{Altered serum cytokines and growth factor profile in individuals with metablolic syndrome}

As shown in Table 3, individuals with the MetS had significantly higher serum concentrations of IL- $1 \alpha /-\beta /-2 /-4 /-6 /-8 /-$ 10, TNF- $\alpha$, IFN- $\gamma$, MCP-1 and EGF compared with the control group $(P<0.05)$. Conversely, the serum concentration of VEGF was significantly lower in individuals with the MetS $(P<0 \cdot 05$; Table 3). Based on these results, we built two separate networks and functional analyses; the first was composed of all possible interactions for cytokines, while the second included interactions retrieved for proteins that had a differential expression (Fig. 1). These analyses showed the physical interaction of cytokines and growth factors in patients with the MetS, suggesting that IL-6/8, VEGF, TNF and chemokine
Table 1. Characteristics data from all subjects in each group*

(Mean values and standard deviations; number of participants and percentages; median values and interquartile ranges (IQR))

\begin{tabular}{|c|c|c|c|c|c|}
\hline \multirow[b]{2}{*}{ Characteristics } & \multicolumn{2}{|c|}{ MetS - $(n$ 148) } & \multicolumn{2}{|c|}{ MetS+ $(n$ 155) } & \multirow[b]{2}{*}{$P$} \\
\hline & Mean & SD & Mean & SD & \\
\hline Age (years) & 1078 & 53.55 & 53.91 & $7 \cdot 61$ & 0.740 \\
\hline \multicolumn{5}{|l|}{ Sex } & 0.872 \\
\hline \multicolumn{6}{|l|}{ Male } \\
\hline$n$ & \multicolumn{2}{|c|}{73} & \multicolumn{2}{|c|}{74} & \\
\hline$\%$ & \multicolumn{2}{|c|}{$48 \cdot 7$} & \multicolumn{2}{|c|}{$47 \cdot 7$} & \\
\hline \multicolumn{6}{|l|}{ Female } \\
\hline$n$ & \multicolumn{2}{|c|}{77} & \multicolumn{2}{|c|}{81} & \\
\hline$\%$ & \multicolumn{2}{|c|}{$51 \cdot 3$} & \multicolumn{2}{|c|}{$52 \cdot 3$} & \\
\hline Current smoker & & & & & $<0.001$ \\
\hline \multicolumn{6}{|l|}{ Yes } \\
\hline$n$ & \multicolumn{2}{|c|}{127} & \multicolumn{2}{|c|}{40} & \\
\hline$\%$ & \multicolumn{2}{|c|}{$84 \cdot 7$} & \multicolumn{2}{|c|}{$30 \cdot 8$} & \\
\hline \multicolumn{6}{|l|}{ No } \\
\hline$n$ & \multicolumn{2}{|c|}{23} & \multicolumn{2}{|c|}{90} & \\
\hline$\%$ & \multicolumn{2}{|c|}{$15 \cdot 3$} & \multicolumn{2}{|c|}{$69 \cdot 2$} & \\
\hline Former smoker & & & & & $<0.001$ \\
\hline Yes & & & & & \\
\hline$n$ & & & & & \\
\hline$\%$ & & & & & \\
\hline No & & & & & \\
\hline$n$ & & & & & \\
\hline$\%$ & & & & & \\
\hline Height (cm) & $8 \cdot 84$ & $161 \cdot 75$ & $161 \cdot 39$ & $8 \cdot 20$ & 0.743 \\
\hline Weight (kg) & $11 \cdot 70$ & 65.54 & 80.98 & $12 \cdot 04$ & $<0.001$ \\
\hline BMI $\left(\mathrm{kg} / \mathrm{m}^{2}\right)$ & $4 \cdot 20$ & $25 \cdot 24$ & $31 \cdot 10$ & 3.98 & $<0.001$ \\
\hline WC (cm) & $12 \cdot 61$ & $91 \cdot 33$ & $104 \cdot 81$ & $8 \cdot 80$ & $<0.001$ \\
\hline $\mathrm{HC}(\mathrm{cm})$ & $8 \cdot 50$ & 99.80 & $109 \cdot 84$ & $8 \cdot 13$ & $<0.001$ \\
\hline Fat percentage & $30 \cdot 25$ & $10 \cdot 62$ & 34.87 & $8 \cdot 85$ & 0.001 \\
\hline Waist:hip ratio & 0.91 & 08 & 0.95 & 0.06 & $<0.001$ \\
\hline LDL-C (mmol/l) & $3 \cdot 14$ & 0.79 & $3 \cdot 23$ & 0.91 & 0.384 \\
\hline $\mathrm{TC}(\mathrm{mmol} / \mathrm{l})$ & $5 \cdot 00$ & 0.95 & 5.09 & 1.07 & 0.468 \\
\hline TAG (mmol/l) & & & & & $<0.001$ \\
\hline Median & & & & & \\
\hline IQR & 1.0 & 1.91 & $1 \cdot 20$ & 51 & \\
\hline $\mathrm{HDL}-\mathrm{C}(\mathrm{mmol} / \mathrm{l})$ & $1 \cdot 12$ & 0.22 & 1.05 & 0.21 & 0.003 \\
\hline $\mathrm{SBP}(\mathrm{mmHg})$ & 17.97 & 121.57 & $131 \cdot 78$ & $17 \cdot 91$ & $<0.001$ \\
\hline $\mathrm{DBP}(\mathrm{mmHg})$ & $10 \cdot 75$ & 78.66 & 85.88 & $10 \cdot 78$ & $<0.001$ \\
\hline $\mathrm{FBG}(\mathrm{mmol} / \mathrm{l})$ & $50 \cdot 40$ & 94.47 & $108 \cdot 18$ & $36 \cdot 80$ & 0.009 \\
\hline hs-CRP (mg/l) & & & & & $<0.001$ \\
\hline Median & & & & & \\
\hline IQR & $10 \cdot$ & $25 \cdot 0$ & $20 \cdot 0$ & $2 \cdot 3$ & \\
\hline
\end{tabular}

MetS, metabolic syndrome; WC, waist circumference; HC, hip circumference; LDL-C, LDL cholesterol; TC, total cholesterol; HDL-C, HDL cholesterol; SBP systolic blood pressure; DBP, diastolic blood pressure; FBG, fasting blood glucose; hs-CRP, high-sensitivity C-reactive protein.

*Student's $t$ test and Mann-Whitney $U$ test were used to compare the demographic and clinical characteristics in normally and non-normally distributed variables, respectively.

(C-C motif) ligand 2 (MCP-1) were activated, followed by induction of IL-1A/-1B (Fig. 1)

\section{Association of serum cytokine and growth factor}

We also evaluated the correlation between the cytokines and growth factors in each group (Tables 4 and 5). This additional analysis revealed a significant correlation between the expression levels of IL- 8 and TNF- $\alpha(P<0.001, r$ 0.287) or IFN- $\gamma$ and IL-4 $(P=0.002, r \quad 0.256)$ or IL- 4 and VEGF $(P=0.001, \quad r-0.272)$ in individuals without the MetS. However, we observed a significant correlation between 
Table 2. Comparison of the dietary intake of macronutrients between subjects under study * (Mean values and standard deviations)

\begin{tabular}{|c|c|c|c|c|c|}
\hline \multirow[b]{2}{*}{ Macronutrients } & \multicolumn{2}{|c|}{ MetS- $(n 150)$} & \multicolumn{2}{|c|}{ MetS+ $(n$ 155) } & \multirow[b]{2}{*}{$P$} \\
\hline & Mean & SD & Mean & SD & \\
\hline Energy intake (kcal) & $1881 \cdot 7$ & $761 \cdot 2$ & $1650 \cdot 3$ & $642 \cdot 8$ & 0.027 \\
\hline Energy intake (kJ) & 7873.0 & 3184.9 & 6904.9 & 2689.5 & 0.027 \\
\hline Protein $(\mathrm{g})$ & $72 \cdot 6$ & 37.4 & $61 \cdot 6$ & $28 \cdot 8$ & 0.028 \\
\hline Adjusted protein (g) & 67.4 & $24 \cdot 8$ & $64 \cdot 9$ & $17 \cdot 4$ & 0.434 \\
\hline Carbohydrate (g) & $250 \cdot 2$ & $110 \cdot 1$ & 235.9 & $117 \cdot 3$ & 0.396 \\
\hline Adjusted carbohydrate (g) & $234 \cdot 1$ & 54.4 & $252 \cdot 1$ & $52 \cdot 0$ & 0.024 \\
\hline Starch $(g)$ & $150 \cdot 8$ & $89 \cdot 2$ & $143 \cdot 3$ & $75 \cdot 1$ & 0.546 \\
\hline Adjusted starch (g) & $138 \cdot 7$ & $70 \cdot 2$ & $150 \cdot 4$ & 37.9 & 0.179 \\
\hline Sugar $(g)$ & 94.5 & $68 \cdot 3$ & 90.5 & $69 \cdot 8$ & 0.696 \\
\hline Adjusted sugar (g) & $98 \cdot 7$ & $55 \cdot 3$ & $107 \cdot 4$ & $56 \cdot 3$ & 0.303 \\
\hline Fibre $(\mathrm{g})$ & 18.5 & $12 \cdot 5$ & $15 \cdot 1$ & 9.7 & 0.053 \\
\hline Adjusted fibre (g) & 21.9 & $9 \cdot 3$ & $21 \cdot 1$ & $6 \cdot 6$ & 0.531 \\
\hline Total fat $(\mathrm{g})$ & $72 \cdot 1$ & $38 \cdot 1$ & $57 \cdot 8$ & $24 \cdot 6$ & 0.003 \\
\hline Adjusted total fat (g) & $67 \cdot 1$ & $20 \cdot 4$ & $61 \cdot 1$ & $19 \cdot 0$ & 0.041 \\
\hline Cholesterol (mg) & $229 \cdot 4$ & 171.4 & $202 \cdot 4$ & $141 \cdot 0$ & 0.254 \\
\hline Adjusted cholesterol (mg) & $220 \cdot 6$ & $167 \cdot 2$ & 207.4 & $132 \cdot 3$ & 0.561 \\
\hline SFA (g) & $18 \cdot 6$ & $10 \cdot 4$ & 14.9 & $7 \cdot 1$ & 0.008 \\
\hline Adjusted SFA (g) & $141 \cdot 2$ & $7 \cdot 1$ & 139.5 & $6 \cdot 7$ & 0.112 \\
\hline Trans fatty acids (g) & 0.93 & 0.69 & 0.78 & 0.68 & $0 \cdot 151$ \\
\hline Adjusted trans fatty acids (g) & 1.8 & 0.5 & 1.8 & 0.6 & 0.530 \\
\hline MÚFA (g) & $19 \cdot 7$ & $10 \cdot 3$ & $15 \cdot 3$ & 6.5 & 0.001 \\
\hline Adjusted MUFA (g) & $158 \cdot 1$ & $6 \cdot 7$ & $156 \cdot 0$ & 5.5 & 0.019 \\
\hline PUFA (g) & $26 \cdot 1$ & 17.5 & $19 \cdot 0$ & $9 \cdot 0$ & 0.001 \\
\hline Adjusted PUFA (g) & 24.9 & $12 \cdot 1$ & $21 \cdot 0$ & $9 \cdot 3$ & 0.017 \\
\hline
\end{tabular}

MetS, metabolic syndrome.

*The dietary intake was adjusted based on total energy intake, as described previously ${ }^{(44)}$

some of cytokines in the MetS group (e.g. correlation of IL-6 with IL-8, $P=0 \cdot 001, r 0 \cdot 274$, Tables 4 and 5).

\section{Association of serum cytokine and growth factor profiles with the metabolic syndrome}

To evaluate the association of serum cytokine and growth factor concentrations with the MetS, univariate and multivariate analyses were employed (Table 6). This analysis showed an independent significant $(P<0.05)$ relationship between the presence of the MetS and serum concentrations of IL- $1 \alpha$, IL-1 $\beta$, IL-2, IL- 4 , IL-6, IL-8, IL-10, IFN- $\gamma$, TNF- $\alpha$, VEGF and MCP-1, after removing the effects of age, sex and smoking. IFN- $\gamma$ and IL- $1 \alpha$ showed the greatest independent association with the MetS (Table 6). Then we created an inflammatory score to provide a summary statistic representative of the panel of markers using regression

Table 3. Serum concentration of cytokines and growth factors levels in two groups with and without the metabolic syndrome (MetS)*

(Median values and interquartile ranges (IQR))

\begin{tabular}{|c|c|c|c|c|c|}
\hline \multirow[b]{2}{*}{ Cytokines and GF† } & \multicolumn{2}{|c|}{ MetS- $(n$ 148) } & \multicolumn{2}{|c|}{ MetS+ $(n$ 155) } & \multirow[b]{2}{*}{$P$} \\
\hline & Median & IQR & Median & IQR & \\
\hline IL-2 & $2 \cdot 70$ & $2 \cdot 50-3 \cdot 15$ & 2.85 & $2.42-3.70$ & 0.024 \\
\hline IL-4 & 1.91 & $1 \cdot 63-2 \cdot 36$ & $2 \cdot 34$ & $1.82-2.79$ & $<0.001$ \\
\hline IL-6 & 0.89 & $0.62-1.78$ & 1.24 & $0.63-3.03$ & 0.017 \\
\hline IL-8 & 4.48 & $3.05-5.73$ & $7 \cdot 64$ & $3.50-25.78$ & $<0.001$ \\
\hline IL-10 & 0.83 & $0.70-1.23$ & 0.91 & $0.76-1.66$ & 0.002 \\
\hline VEGF & $82 \cdot 18$ & $42 \cdot 44-153 \cdot 19$ & 38.55 & $18 \cdot 00-99 \cdot 11$ & $<0.001$ \\
\hline IFN- $\gamma$ & 0.57 & $0.54-0.57$ & 1.58 & $0.71-1.58$ & $<0.001$ \\
\hline TNF- $\alpha$ & 0.56 & $1.15-2.01$ & 0.60 & $1 \cdot 14-2 \cdot 36$ & 0.018 \\
\hline $\mathrm{IL}-1 \alpha$ & 0.52 & $0.48-0.60$ & 0.54 & $0.51-0.73$ & $<0.001$ \\
\hline IL-1 $1 \beta$ & 0.54 & $0.42-0.70$ & 0.67 & $0.46-1.11$ & $<0.001$ \\
\hline MCP-1 & $33 \cdot 79$ & $19.91-55.86$ & $108 \cdot 45$ & $42.54-97.90$ & $<0.001$ \\
\hline EGF & $19 \cdot 24$ & $10 \cdot 06-30.39$ & 58.46 & $14 \cdot 66-136 \cdot 78$ & $<0.001$ \\
\hline
\end{tabular}

GF, growth factors; VEGF, vascular endothelial growth factor; IFN- $\gamma$, interferon- $\gamma$; MCP1, monocyte chemo attractant protein; EGF, epidermal growth factor.

* The Mann-Whitney $U$ test was performed.

† Serum cytokines level is expressed as $\mathrm{pg} / \mathrm{ml}$. 

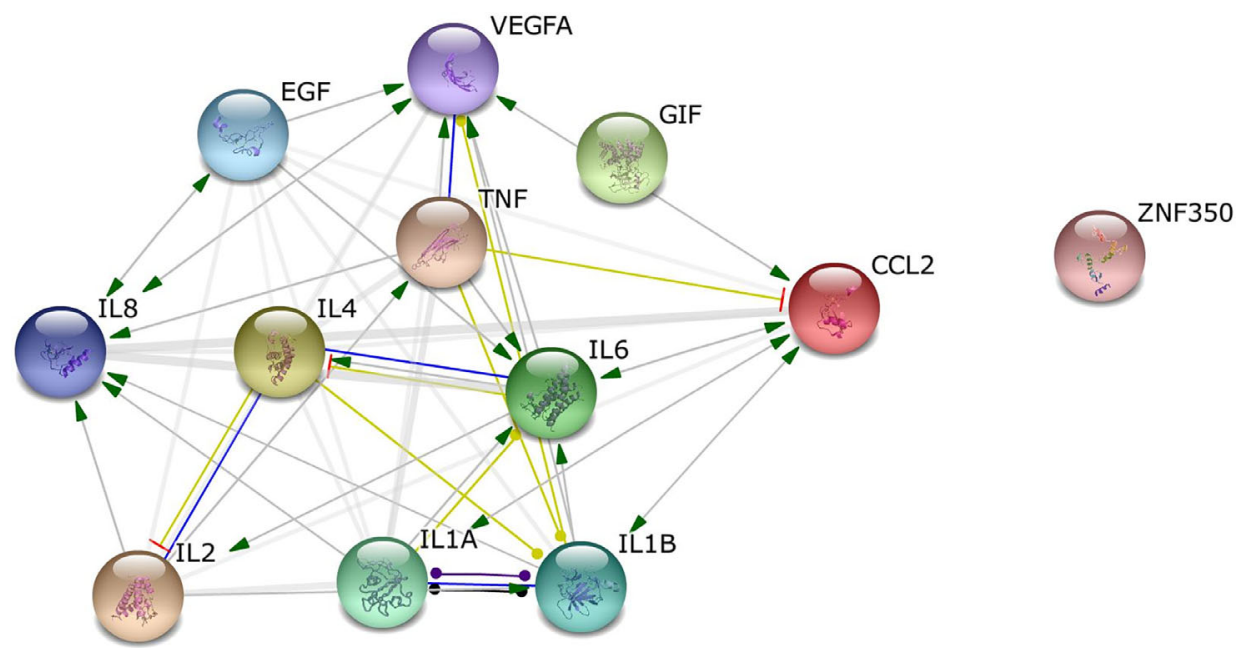

Fig. 1. Network analysis. Functional and physical interactions between pro-inflammatory and anti-inflammatory cytokines and growth factors were retrieved using STRING and data were loaded in Cytoscape version 2.8.3. Arrows show the direction of interaction. CCL2 (monocyte chemo attractant protein-1), GIF (interferon- $\gamma$ ), EGF, epidermal growth factor; VEGF, vascular endothelial growth factor; GIF, anti-interferon gamma antibody. A colour version of this figure can be found online at http://www.journals.cambridge.org/bjn

coefficient of each marker in multivariate model multiple-by variation range of cytokines and growth factors level. This analysis suggested that IFN- $\boldsymbol{\gamma}$ is the factor most related with the MetS (see online Supplementary Table S2).

\section{Discussion}

We have evaluated the association of twelve serum cytokines and growth factors (EGF, IFN- $\gamma$, IL- $1 \alpha /-1 \beta /-2 /-4 /-6 /-8 /-10$, MCP-1, TNF- $\alpha$ and VEGF) in individuals with and without

Table 4. Correlation matrix between growth factors, inflammatory and anti-inflammatory cytokines in the group without the metabolic syndrome ( $n$ 148) using Spearman's correlation analysis

\begin{tabular}{|c|c|c|c|c|c|c|c|c|c|c|c|}
\hline & IL-2 & IL-4 & IL-6 & IL-8 & IL-10 & VEGF & IFN- $\gamma$ & TNF- $\alpha$ & $\mathrm{IL}-1 \alpha$ & IL-1 $\beta$ & MCP-1 \\
\hline \multicolumn{12}{|l|}{ IL-4 } \\
\hline$r$ & 0.109 & & & & & & & & & & \\
\hline$P$ & 0.185 & & & & & & & & & & \\
\hline \multicolumn{12}{|l|}{ IL-6 } \\
\hline$r$ & 0.019 & -0.113 & & & & & & & & & \\
\hline$P$ & 0.820 & 0.168 & & & & & & & & & \\
\hline \multicolumn{12}{|l|}{ IL-8 } \\
\hline$r$ & 0.141 & -0.084 & 0.078 & & & & & & & & \\
\hline$P$ & 0.086 & 0.308 & 0.341 & & & & & & & & \\
\hline \multicolumn{12}{|c|}{ IL-10 } \\
\hline$r$ & 0.101 & 0.106 & 0.061 & -0.128 & & & & & & & \\
\hline$P$ & 0.217 & 0.198 & 0.456 & 0.118 & & & & & & & \\
\hline \multicolumn{12}{|c|}{ VEGF } \\
\hline$r$ & 0.032 & $-0.272^{*}$ & $0.397^{*}$ & $0.221^{*}$ & 0.122 & & & & & & \\
\hline$P$ & 0.700 & 0.001 & $<0.001$ & 0.007 & 0.137 & & & & & & \\
\hline \multicolumn{12}{|c|}{ IFN- $\gamma$} \\
\hline$r$ & 0.021 & $0.256^{*}$ & 0.066 & 0.038 & 0.035 & 0.048 & & & & & \\
\hline$P$ & 0.801 & 0.002 & 0.424 & 0.641 & 0.670 & 0.561 & & & & & \\
\hline \multicolumn{12}{|c|}{ TNF- $\alpha$} \\
\hline$r$ & 0.068 & $-0.208^{\star}$ & $0.393^{\star}$ & $0.287^{*}$ & 0.110 & $0.395^{\star}$ & 0.005 & & & & \\
\hline$P$ & 0.409 & 0.011 & $<0.001$ & $<0.001$ & 0.179 & $<0.001$ & 0.950 & & & & \\
\hline \multicolumn{12}{|c|}{ IL-1 $\alpha$} \\
\hline$r$ & 0.139 & 0.120 & -0.015 & 0.091 & 0.064 & 0.060 & 0.148 & 0.041 & & & \\
\hline$P$ & 0.090 & 0.144 & 0.854 & 0.269 & 0.434 & 0.465 & 0.070 & 0.622 & & & \\
\hline \multicolumn{12}{|c|}{ IL $-1 \beta$} \\
\hline$r$ & 0.075 & -0.100 & $0.222^{*}$ & -0.051 & 0.135 & $0.167^{\star}$ & 0.047 & $0 \cdot 257^{\star}$ & -0.052 & & \\
\hline$P$ & 0.363 & 0.222 & 0.006 & 0.536 & 0.099 & 0.042 & 0.565 & 0.001 & 0.531 & & \\
\hline \multicolumn{12}{|c|}{ MCP-1 } \\
\hline$r$ & $0.174^{*}$ & $0.302^{*}$ & -0.107 & 0.056 & 0.111 & $-0.195^{\star}$ & $0.167^{\star}$ & $-0.218^{\star}$ & 0.058 & $-0.201^{*}$ & \\
\hline$P$ & 0.034 & $<0.001$ & 0.194 & 0.495 & 0.176 & 0.017 & 0.041 & 0.007 & 0.484 & 0.013 & \\
\hline \multicolumn{12}{|l|}{ EGF } \\
\hline$r$ & 0.097 & 0.067 & -0.033 & 0.111 & 0.089 & 0.124 & 0.136 & $0.189^{\star}$ & -0.040 & 0.013 & 0.156 \\
\hline$P$ & 0.240 & 0.413 & 0.684 & 0.174 & 0.276 & 0.130 & 0.096 & 0.021 & 0.625 & 0.873 & 0.056 \\
\hline
\end{tabular}

VEGF, vascular endothelial growth factor; IFN- $\gamma$, interferon- $\gamma$; MCP-1, monocyte chemo attractant protein; EGF, epidermal growth factor.

* Statistically significant $(P<0.05)$. 
Table 5. Correlation matrix between growth factors, inflammatory and anti-inflammatory cytokines in the group with the metabolic syndrome ( $n$ 155) using Spearman's correlation analysis

\begin{tabular}{|c|c|c|c|c|c|c|c|c|c|c|c|}
\hline & IL-2 & IL-4 & IL-6 & IL-8 & IL-10 & VEGF & ING- $\gamma$ & TNF- $\alpha$ & $\mathrm{IL}-1 \alpha$ & $\mathrm{IL}-1 \beta$ & MCP-1 \\
\hline \multicolumn{12}{|l|}{ IL-4 } \\
\hline$r$ & 0.058 & & & & & & & & & & \\
\hline$P$ & 0.477 & & & & & & & & & & \\
\hline \multicolumn{12}{|l|}{ IL-6 } \\
\hline$r$ & -0.039 & -0.139 & & & & & & & & & \\
\hline$P$ & 0.627 & 0.085 & & & & & & & & & \\
\hline \multicolumn{12}{|l|}{ IL-8 } \\
\hline$r$ & -0.058 & -0.074 & $0.274^{*}$ & & & & & & & & \\
\hline$P$ & 0.474 & 0.361 & 0.001 & & & & & & & & \\
\hline \multicolumn{12}{|c|}{ IL-10 } \\
\hline$r$ & 0.110 & 0.140 & -0.007 & 0.019 & & & & & & & \\
\hline$P$ & 0.174 & 0.081 & 0.930 & 0.814 & & & & & & & \\
\hline \multicolumn{12}{|c|}{ VEGF } \\
\hline$r$ & 0.049 & $-0.508^{*}$ & 0.146 & $0.297^{*}$ & -0.075 & & & & & & \\
\hline$P$ & 0.543 & $<0.001$ & 0.070 & $<0.001$ & 0.352 & & & & & & \\
\hline \multicolumn{12}{|c|}{ IFN- $\gamma$} \\
\hline$r$ & -0.023 & $0.295^{\star}$ & -0.004 & 0.048 & $0.171^{*}$ & -0.147 & & & & & \\
\hline$P$ & 0.780 & $<0.001$ & 0.964 & 0.552 & 0.033 & 0.068 & & & & & \\
\hline \multicolumn{12}{|c|}{ TNF- $\alpha$} \\
\hline$r$ & 0.110 & -0.074 & 0.069 & $0 \cdot 241^{*}$ & 0.076 & 0.136 & 0.084 & & & & \\
\hline$P$ & 0.172 & 0.360 & 0.393 & 0.003 & 0.348 & 0.092 & 0.298 & & & & \\
\hline \multicolumn{12}{|l|}{ IL-1 $\alpha$} \\
\hline$r$ & 0.064 & $0.255^{*}$ & -0.025 & 0.079 & 0.113 & -0.151 & 0.155 & 0.117 & & & \\
\hline$P$ & 0.432 & 0.001 & 0.753 & 0.329 & $0 \cdot 161$ & 0.061 & 0.054 & 0.149 & & & \\
\hline \multicolumn{12}{|l|}{ IL-1 $1 \beta$} \\
\hline$r$ & $0 \cdot 220^{\star}$ & $0 \cdot 171^{\star}$ & 0.078 & 0.056 & 0.044 & $-0.174^{\star}$ & -0.022 & 0.031 & $0.219^{*}$ & & \\
\hline$P$ & 0.006 & 0.034 & 0.336 & 0.487 & 0.589 & 0.031 & 0.789 & 0.704 & 0.006 & & \\
\hline \multicolumn{12}{|c|}{ MCP-1 } \\
\hline$r$ & 0.152 & $-0.490^{*}$ & $0.171^{*}$ & $0 \cdot 268^{*}$ & $-0.169^{\star}$ & $0.438^{*}$ & $-0.226^{*}$ & $0.262^{*}$ & -0.123 & 0.020 & \\
\hline$P$ & 0.060 & $<0.001$ & 0.034 & 0.001 & 0.035 & $<0.001$ & 0.005 & 0.001 & 0.129 & 0.807 & \\
\hline \multicolumn{12}{|l|}{ EGF } \\
\hline$r$ & -0.056 & -0.131 & 0.156 & $0.311^{*}$ & 0.023 & $0.418^{*}$ & 0.070 & 0.104 & -0.078 & -0.100 & -0.011 \\
\hline$P$ & 0.490 & 0.104 & 0.053 & $<0.001$ & 0.777 & $<0.001$ & 0.387 & 0.200 & 0.332 & 0.218 & 0.887 \\
\hline
\end{tabular}

VEGF, vascular endothelial growth factor; IFN- $\gamma$, interferon- $\gamma$; MCP-1, monocyte chemo attractant protein; EGF, epidermal growth factor. ${ }^{\star}$ Statistically significant $(P<0.05)$.

the MetS. We found that the serum concentrations of EGF, IFN- $\gamma$, IL- $1 \alpha /-1 \beta /-2 /-4 /-6 /-8 /-10, \quad$ MCP-1 and TNF- $\alpha$ were significantly higher in the individuals with the MetS, while the circulating levels of VEGF were markedly lower in the group with the MetS; these findings are in agreement with previous studies ${ }^{(7)}$.

There is accumulating evidence of an association between the MetS and inflammation ${ }^{(7,23)}$. The increases in serum proinflammatory cytokines, such as IL- 6 and TNF- $\alpha$, are probably related to the enhanced production by the expanded adipose tissue mass ${ }^{(24)}$. It has been suggested that resident monocytederived macrophages in the adipose tissue are a major source of pro-inflammatory cytokines ${ }^{(25)}$. However, little is known about the pro-/anti-inflammatory cytokine and the growth factor profile in this condition. We found significant differences in the concentrations of circulating cytokines and growth factors in the individuals with the MetS. The limited numbers of studies concerning the relationship between inflammation and the MetS as a particular disorder stems from the great overlap between inflammatory features of metabolic disorders such as obesity and diabetes as well as the range of variables involved in the pathogenesis of the MetS. Different components of the MetS have been implicated to be associated with low-grade inflammation mediators including pro-inflammatory, inflammatory and anti-inflammatory markers in numerous studies ${ }^{(8,24)}$. Ridker et al. ${ }^{(26)}$ explored the relationship between CRP, the MetS and incidence of cardiovascular events among 14719 apparently healthy women. They observed that the measurement of CRP could add clinically important prognostic information to the MetS ${ }^{(26)}$. Furthermore, abdominal obesity as a major manifestation of the MetS leads to an increased expression and elaboration of various adipokines, which eventually results in persistent low-grade inflammation.

Here, we observed that individuals with the MetS had a significantly higher concentration of CRP and IL- 6 than individuals without this syndrome. IL- 6 and TNF- $\alpha$ are both expressed in adipose tissue ${ }^{(17,27)}$, and have been reported as two of the most important inflammatory markers associated with the $\mathrm{MetS}^{(18)}$. There is increasing evidence that the elevated circulating levels of IL- 6 , IL- 8 , IL- $1 \beta$ and TNF- $\alpha$ predict the risk of type 2 diabetes ${ }^{(28,29)}$. In addition, in line with a previous finding ${ }^{(30)}$, we observed a significant increase in the concentrations of the aforementioned cytokines and IL-2 in the subjects with the MetS. In agreement with our findings, the correlation between elevated concentrations of IL-2 along with other pro-inflammatory cytokines and occurrence of metabolic disorders such as diabetes mellitus has been 
Table 6. Association between cytokine and growth factor concentrations and the metabolic syndrome†

(Odds ratios and $95 \%$ confidence intervals)

\begin{tabular}{|c|c|c|c|c|c|c|}
\hline & \multicolumn{3}{|c|}{ Univariate } & \multicolumn{3}{|c|}{ Multivariate } \\
\hline & OR & $95 \% \mathrm{Cl}$ & $P$ & $\mathrm{OR}^{*}$ & $95 \% \mathrm{Cl}$ & $P^{\star}$ \\
\hline IL-2 & 1.86 & $1.34,2.59$ & $<0.001$ & 1.77 & $1 \cdot 15,2 \cdot 55$ & 0.031 \\
\hline IL-4 & 1.99 & $1 \cdot 38,2 \cdot 87$ & $<0.001$ & 2.05 & $1 \cdot 10,2 \cdot 69$ & 0.020 \\
\hline IL-6 & 1.34 & $1 \cdot 12,1.60$ & 0.001 & 1.47 & $1.12,1.68$ & 0.002 \\
\hline IL-8 & 1.13 & $1.07,1.19$ & $<0.001$ & $1 \cdot 13$ & $1 \cdot 06,1 \cdot 18$ & $<0.001$ \\
\hline IL-10 & $1 \cdot 17$ & $0.98,1.40$ & 0.078 & & & \\
\hline VEGF & 0.995 & $0.993,0.998$ & 0.001 & 0.99 & $0.991,1.008$ & 0.064 \\
\hline IFN- $\gamma$ & $4 \cdot 34$ & $2 \cdot 04,7 \cdot 84$ & $<0.001$ & 3.87 & $1.81,6.54$ & $<0.001$ \\
\hline TNF- $\alpha$ & 1.55 & $1.20,1.98$ & 0.001 & 1.45 & $1.07,1.99$ & 0.039 \\
\hline $\mathrm{IL}-1 \alpha$ & $3 \cdot 23$ & $1.94,5 \cdot 89$ & $<0.001$ & $2 \cdot 28$ & $0.79,4.92$ & 0.049 \\
\hline IL-1 $1 \beta$ & $2 \cdot 34$ & $1 \cdot 15,3.67$ & $<0.001$ & $2 \cdot 01$ & $1.04,3.45$ & 0.021 \\
\hline MCP-1 & 1.02 & $1.01,1.03$ & $<0.001$ & 1.012 & $1.007,1.018$ & 0.009 \\
\hline EGF & 1.01 & $1.00,1.02$ & $<0.001$ & 1.007 & $1.002,1.011$ & $<0.001$ \\
\hline hs-CRP & 1.39 & $1.07,1.77$ & $<0.001$ & $1 \cdot 14$ & $1.02,1.27$ & 0.046 \\
\hline
\end{tabular}

VEGF, vascular endothelial growth factor; IFN- $\gamma$, interferon- $\gamma$, MCP-1, monocyte chemoattractant protein; EGF, epidermal growth factor; hs-CRP, high-sensitivity C-reactive protein.

* In present of age, sex, smoking and dietary intake (including energy intake, protein, adjusted carbohydrate, adjusted total fat SFA, adjusted MUFA and adjusted PUFA, which were significantly different between groups). Multivariate analysis was done when $P$ value of univariate was $<0.05$.

$\dagger$ Association of inflammatory markers level with the metabolic syndrome in calculated by binary logistic regression model.

demonstrated in several studies ${ }^{(30)}$. The potential protective effects of some anti-inflammatory factors against metabolic disturbances associated with adiposity, including glucose intolerance $^{(31)}$. We found significantly higher levels of serum anti-inflammatory cytokines, IL- 4 and IL-10 in the individuals with the MetS; the reason for this is uncertain, but may be a compensatory response to the overall pro-inflammatory state. Makki et $a l .{ }^{(32)}$ have recently described that the activation of EGF receptor is implicated in blood pressure regulation, endothelial dysfunction, atherogenesis and cardiac remodelling, and increased circulating EGF-like ligands might mediate vascular disease associated with chronic inflammation. We found higher concentrations of serum EGF and lower concentration of VEGF in the group of individuals with the MetS than in the control subjects. We also found a correlation between VEGF with TNF- $\alpha$ in the control group. This is in accord with the work reported by Azimi-Nezhad et $a l{ }^{(33)}$, who found that VEGF expression is modulated by TNF- $\alpha$ in peripheral blood mononuclear cells, which might be a plausible connection between VEGF and inflammatory markers; however, further studies are needed to explore their cross talk.

There is a growing body of evidence showing a relationship between chronic inflammation and the disruption of cellular metabolism $^{(34,35)}$. Zhang and collaborators ${ }^{(36)}$ showed that mast cells contributed to the pathogenesis of type 2 diabetes by generating of IFN- $\boldsymbol{\gamma}$. IFN- $\boldsymbol{\gamma}$ desensitises adipocyte to insulin and inhibits the maturation of pre-adipocyte in a Janus kinase 1 /signal transducer and activator of transcription 1 (JAK1/STAT1) dependent manner. Moreover, IFN- $\gamma$ disrupts energy expenditure and metabolic homeostasis ${ }^{(37)}$. In the present study, we observed that serum concentration of IFN- $\gamma$ significantly increased from $0.57 \mathrm{pg} / \mathrm{ml}$ (interquartile range $0.54-0.57$ ) to $1.58 \mathrm{pg} / \mathrm{ml}$ (interquartile range $0.71-1.58$ ),
$P<0.05$ and was associated with higher OR (3.87) in the MetS group, compared to other markers, as determined by univariate and multivariate analysis. Additional cluster analysis using regression coefficient of each of the cytokines/growth factor in multivariate model multiple-by variation range of each marker suggested IFN- $\gamma$ as the most related factor, with the MetS among the top thirteen markers. Similar results were observed for IL- $1 \alpha$ as the most related factor with the MetS after IFN- $\boldsymbol{\gamma}$, showing that patients with the MetS had an OR of $2.28(P=0.049)$ after adjustment for age, sex, smoking and dietary intake. In line with our observation, Um et al. ${ }^{(38)}$ have proposed that IL- $1 \alpha$, a pro-inflammatory cytokine secreted from adipose tissue, contributes to the morbidity associated with obesity and $\mathrm{CVD}^{(39,40)}$. In addition, network analysis illustrated potential interaction of cytokines and growth factors in MetS patients, suggesting the activation of IL-6/8 and TNF via induction of IL-1. In turn, IFN- $\gamma$ induces nuclear translocation of $\mathrm{NF}-\mathrm{\kappa B}^{(41)}$, which is the major transcription factor mediating the transcriptional activation of $\mathrm{TNF}-\alpha$ and inflammatory genes in cellular response to the environmental factors $^{(42)}$. TNF is shown to activate the mammalian target of rapamycin signalling pathway, which is associated with insulin resistance and diabetic complications ${ }^{(43)}$

A strength of the present study is that it was conducted in a well-characterised cohort of individuals, with or without the MetS, in whom a simultaneous profile of several potentially important cytokines was assessed. The main limitations were the cross-sectional study design and modest sample size. It has been shown that certain dietary components, found in fruits, berries, vegetables, nuts, whole grains, and foods of marine origin, might play a crucial role in reducing and mitigating chronic pro-inflammatory processes associated with chronic diseases. In the present study, we adjusted the effects of macronutrient intake ${ }^{(44)}$, which were significantly different 
between the groups in multivariate analysis to explore the association of cytokines and growth factor with the MetS (Table 6). It is possible that other lifestyle characteristics such as micronutrients may have an important influence on the cytokine profile. In particular, it has been suggested that culinary herbs and spices have anti-inflammatory activities and the extent to which they activate PPAR $\alpha$ and PPAR $\gamma$ inhibit the activation of NF- $\mathrm{KB}$ and enhance expression of anti-inflammatory cytokines ${ }^{(45)}$, which might explain at least in part the inverse effect of some anti-inflammatory cytokines in our population. The impact of treatment with antiinflammatory agents on the biochemical and clinical outcomes of individuals with the MetS would clearly be important to explore, as would the value of cytokine profiles in predicting MetS patients. Moreover, in the present study we did not evaluate the relation between complement component 3 (C3) and the MetS, supporting further investigation on the role of this factor in the MetS.

In conclusion, we have shown that individuals with the MetS have altered levels of circulating pro- and anti-inflammatory cytokines and growth factors that may be implicated in clinical outcomes. Further multi-centre and prospective trials are required to unravel the role and association of emerging inflammatory markers with the MetS and cardiovascular outcomes.

\section{Supplementary material}

To view supplementary material for this article, please visit http://dx.doi.org/10.1017/S0007114515001038

\section{Acknowledgements}

We would like to thank all the patients for their help and participating in the study.

This work was supported by the grant from MUMS, Research Council (M. G.-M., S. R. M., A. A. and A. P.). The results obtained in the present study are part of Mr Seyed Reza Mirhafez's PhD thesis (ID no. 910823) in MUMS. MUMS had no role in the design, analysis or writing of this article.

The authors' contributions are as follows: M. G.-M., A. P. and Z. M. contributed to the study design; S. R. M., M. M. and A. R. H.-B. conducted the experimental part; S. R. M., M. G.-M., H. R. R., S. E., H. M.-M., H. E. and A. M. contributed to the data analysis; S. R. M., A. P., A. A., G. A. F., A. P. and M. G.-M. contributed to the preparation of the manuscript.

The authors have no conflict of interest.

\section{References}

1. Grundy SM, Cleeman JI, Daniels SR, et al. (2006) Diagnosis and management of the metabolic syndrome: an American Heart Association/National Heart, Lung, and Blood Institute scientific statement. Curr Opin Cardiol 21, 1-6.

2. Isomaa B, Almgren P, Tuomi T, et al. (2001) Cardiovascular morbidity and mortality associated with the metabolic syndrome. Diabetes Care 24, 683-689.

3. Lakka HM, Laaksonen DE, Lakka TA, et al. (2002) The metabolic syndrome and total and cardiovascular disease mortality in middle-aged men. JAMA 288, 2709-2716.
4. Girman CJ, Rhodes T, Mercuri M, et al. (2004) The metabolic syndrome and risk of major coronary events in the Scandinavian Simvastatin Survival Study (4S) and the Air Force/ Texas Coronary Atherosclerosis Prevention Study (AFCAPS/ TexCAPS). Am J Cardiol 93, 136-141.

5. Malik S, Wong ND, Franklin SS, et al. (2004) Impact of the metabolic syndrome on mortality from coronary heart disease, cardiovascular disease, and all causes in United States adults. Circulation 110, 1245-1250.

6. Grundy SM, Hansen B, Smith SC, et al. (2004) Clinical management of metabolic syndrome report of the American Heart Association/National Heart, Lung, and Blood Institute/ American Diabetes Association conference on scientific issues related to management. Circulation 109, 551-556.

7. Sutherland JP, McKinley B \& Eckel RH (2004) The metabolic syndrome and inflammation. Metab Syndr Relat Disord 2, $82-104$.

8. Berg AH \& Scherer PE (2005) Adipose tissue, inflammation, and cardiovascular disease. Circ Res 96, 939-949.

9. Frohlich M, Imhof A, Berg G, et al. (2000) Association between C-reactive protein and features of the metabolic syndrome: a population-based study. Diabetes Care 23, $1835-1839$.

10. Ford ES (2003) The metabolic syndrome and C-reactive protein, fibrinogen, and leukocyte count: findings from the Third National Health and Nutrition Examination Survey. Atherosclerosis 168, 351-358.

11. Edalat B, Sharifi F, Badamchizadeh Z, et al. (2013) Association of metabolic syndrome with inflammatory mediators in women with previous gestational diabetes mellitus.J Diabetes Metab Disord 12, 8.

12. Van Exel E, Gussekloo J, de Craen AJ, et al. (2002) Low production capacity of interleukin-10 associates with the metabolic syndrome and type 2 diabetes: the Leiden 85-Plus Study. Diabetes 51, 1088-1092.

13. Moon YS, Kim DH \& Song DK (2004) Serum tumor necrosis factor-alpha levels and components of the metabolic syndrome in obese adolescents. Metabolism 53, 863-867.

14. Yudkin JS, Juhan-Vague I, Hawe E, et al. (2004) Low-grade inflammation may play a role in the etiology of the metabolic syndrome in patients with coronary heart disease: the HIFMECH study. Metabolism 53, 852-857.

15. Choi K, Lee J, Lee K, et al. (2004) Comparison of serum concentrations of C-reactive protein, TNF- $\alpha$, and interleukin 6 between elderly Korean women with normal and impaired glucose tolerance. Diabetes Res Clin Pract 64, 99-106.

16. Salmenniemi U, Ruotsalainen E, Pihlajamäki J, et al. (2004) Multiple abnormalities in glucose and energy metabolism and coordinated changes in levels of adiponectin, cytokines, and adhesion molecules in subjects with metabolic syndrome. Circulation 110, 3842-3848.

17. Matsushita K, Yatsuya H, Tamakoshi K, et al. (2006) Comparison of circulating adiponectin and proinflammatory markers regarding their association with metabolic syndrome in Japanese men. Arterioscler Thromb Vasc Biol 26, 871-876.

18. Kern PA, Ranganathan S, Li C, et al. (2001) Adipose tissue tumor necrosis factor and interleukin-6 expression in human obesity and insulin resistance. Am J Physiol Endocrinol Metab 280, 745-751.

19. Mirhafez SR, Mohebati M, Feiz Disfani MP, et al. (2014) An imbalance in serum concentrations of inflammatory and anti-inflammatory cytokines in hypertension. $J$ Am Soc Hypertens 8, 614-623.

20. Molloy RM, Mc Connell RI, Lamont JV, et al. (2005) Automation of biochip array technology for quality results. Clin Chem Lab Med 43, 1303-1313. 
21. Fitzgerald SP, Lamont JV, McConnell RI, et al. (2005) Development of a high-throughput automated analyzer using biochip array technology. Clin Chem 51, 1165-1176.

22. Nepusz T, Yu H \& Paccanaro A (2012) Detecting overlapping protein complexes in protein-protein interaction networks. Nat Methods 9, 471-472

23. Eckel RH, Grundy SM \& Zimmet PZ (2005) The metabolic syndrome. Lancet 365, 1415-1428.

24. Fernández Real JM \& Ricart W (2003) Insulin resistance and chronic cardiovascular inflammatory syndrome. Endocr Rev 24, 278-301.

25. Trayhurn P \& Wood IS (2004) Adipokines: inflammation and the pleiotropic role of white adipose tissue. BrJ Nutr 92, 347-355.

26. Ridker PM, Buring JE, Cook NR, et al. (2003) C-reactive protein, the metabolic syndrome, and risk of incident cardiovascular events: an 8-year follow-up of 14719 initially healthy American women. Circulation 107, 391-397.

27. Miyazaki Y, Pipek R, Mandarino LJ, et al. (2003) Tumor necrosis factor alpha and insulin resistance in obese type 2 diabetic patients. Int J Obes Relat Metab Disord 27, 88-94.

28. Giulietti A, van Etten E, Overbergh L, et al. (2007) Monocytes from type 2 diabetic patients have a pro-inflammatory profile. 1,25-Dihydroxyvitamin D(3) works as anti-inflammatory. Diabetes Res Clin Pract 77, 47-57.

29. Odegaard JI \& Chawla A (2012) Connecting type 1 and type 2 diabetes through innate immunity. Cold Spring Harb Perspect Med 2, a007724.

30. Yaturu S, Rains J \& Jain SK (2008) Relationship of elevated osteoprotegerin with insulin resistance, CRP, and TNF-alpha levels in men with type 2 diabetes. Cytokine 44, 168-171.

31. Fleischman A, Shoelson SE, Bernier R, et al. (2008) Salsalate improves glycemia and inflammatory parameters in obese young adults. Diabetes Care 31, 289-294.

32. Makki N, Thiel KW \& Miller FJ (2013) The epidermal growth factor receptor and its ligands in cardiovascular disease. Int J Mol Sci 14, 20597-20613.

33. Azimi-Nezhad M, Stathopoulou MG, Bonnefond A, et al. (2013) Associations of vascular endothelial growth factor
(VEGF) with adhesion and inflammation molecules in a healthy population. Cytokine 61, 602-607.

34. Emanuela F, Grazia M, Marco de R, et al. (2012) Inflammation as a link between obesity and metabolic syndrome. J Nutr Metab 2012, 476380

35. Hotamisligil GS \& Erbay E (2008) Nutrient sensing and inflammation in metabolic diseases. Nat Rev Immunol $\mathbf{8}$, 923-934.

36. Zhang J \& Shi GP (2012) Mast cells and metabolic syndrome. Biochim Biophys Acta 1822, 14-20.

37. Li P, Zhao Y, Wu X, et al. (2012) Interferon gamma (IFN- $\gamma$ ) disrupts energy expenditure and metabolic homeostasis by suppressing SIRT1 transcription. Nucleic Acids Res $\mathbf{4 0}$ 1609-1620.

38. Um JY, Rim HK, Kim SJ, et al. (2012) Functional polymorphism of IL-1 alpha and its potential role in obesity in humans and mice. PLOS ONE 6, e29524.

39. Mehra VC, Ramgolam VS \& Bender JR (2005) Cytokines and cardiovascular disease. J Leukoc Biol 78, 805-818.

40. Fearon WF \& Fearon DT (2008) Inflammation and cardiovascular disease: role of the interleukin-1 receptor antagonist. Circulation 117, 2577-2579.

41. Li L, Wang L, Wu Z, et al. (2014) Anthocyanin-rich fractions from red raspberries attenuate inflammation in both RAW264.7 macrophages and a mouse model of colitis. Sci Rep 4, 6234 .

42. Zhou A, Scoggin S, Gaynor RB, et al. (2003) Identification of NF-кB-regulated genes induced by TNF $\alpha$ utilizing expression profiling and RNA interference. Oncogene 22, 2054-2064.

43. Blagosklonny MV (2013) TOR-centric view on insulin resistance and diabetic complications: perspective for endocrinologists and gerontologists. Cell Death Dis $\mathbf{4}$, e964.

44. Nazeminezhad R, Tajfard M, Latiff LA, et al. (2014) Dietary intake of patients with angiographically defined coronary artery disease and that of healthy controls in Iran. Eur $J$ Clin Nutr 68, 109-113.

45. Jungbauer A \& Medjakovic S (2012) Anti-inflammatory properties of culinary herbs and spices that ameliorate the effects of metabolic syndrome. Maturitas 71, 227-239. 